\title{
DESIGN PRINCIPLES TO INCREASE THE PATIENT SPECIFICITY OF HIGH TIBIAL OSTEOTOMY FIXATION DEVICES
}

\author{
Kanagalingam, Sanjeevan (1); Shepherd, Duncan (1); Fernandez-Vicente, Miguel (2); Wimpenny, \\ David (2); Thomas-Seale, Lauren (1) \\ 1: School of Engineering, University of Birmingham, UK; 2: Manufacturing Technology Centre, \\ Coventry, UK
}

\begin{abstract}
High stiffness fracture fixation devices inducing absolute stability, activate inefficient primary healing and stress shielding. Taking High Tibial Osteotomy as a representative example, review of the clinical literature and mapping the fracture healing process revealed two physically contradicting requirements, which are only partially met by current techniques. Stiffness of the fixation is required immediately after fracture, however in the remodelling phase this can cause stress shielding. Stability is required immediately after fracture, however in the ossification phase less stability is required to stimulate secondary (and more efficient) healing. This study evaluates the use of the TRIZ Inventive Design Principles to overcome these physical contradictions. Six designs concepts were evaluated, of which the Macro-Geometry stiffness modulated design was ranked the highest. This was achieved through spatial decomposition of the problem utilising the Inventive Principles of Asymmetry, Extraction and Local Quality. This study offer perspectives on how to increase the patient specificity of fixation utilising the increased topology freedom of design for additive manufacture (AM).
\end{abstract}

Keywords: Biomedical design, Additive Manufacturing, Conceptual design, TRIZ, Design methodology

Contact:

Kanagalingam, Sanjeevan

University Of Birmingham

Mechanical Engineering

United Kingdom

sxk153@bham.ac.uk

Cite this article: Kanagalingam, S., Shepherd, D., Fernandez-Vicente, M., Wimpenny, D., Thomas-Seale, L. (2019)

'Design Principles to Increase the Patient Specificity of High Tibial Osteotomy Fixation Devices', in Proceedings of the 22nd International Conference on Engineering Design (ICED19), Delft, The Netherlands, 5-8 August 2019. DOI: $10.1017 /$ dsi.2019.96 


\section{INTRODUCTION}

The aim of this study is to evaluate whether the use of The Theory of Inventive Problem Solving inventive principles can increase the patient specificity of fixation for High Tibial Osteotomy (HTO), to overcome the psychological inertia which limits the creative scope of design for additive manufacture (DfAM). Fracture is a medical condition resulting in complete or partial structural discontinuity of bone following a trauma, pathology or overuse. Court-Brown and Caesar (2006), estimates a world incidence of between 9.0 and 22.8 fractures per thousand people annually. Of these, 9 million are osteoporotic fractures (Johnell and Kanis, 2004) which alone account for 37 billion Euros across the 27 countries of the European Union (Hernlund et al., 2013). Due to the increase in life expectancy, the epidemiology of fractures is shifting rapidly (Ensrud, 2013), which has resulted in a $25 \%$ increase in global costs of osteoporotic fractures from 2010 to 2025 (Hernlund et al., 2013). The primary goal of surgical treatment is to provide optimal fixation that allows for a range of motion and to achieve healing without loss of alignment and fixation. Fracture reduction is achieved directly by interfragmentary compression (absolute stability) or indirectly with interfragmentary motion (relative stability) which regenerates bone by means of primary or secondary healing (Marsell and Einhorn, 2011).

Internal fixation by plate osteosysnthesis has been a method of fracture management since the late 1800s, continuously evolving from conventional compression plates to the current clinical practices of locking plates incorporating dynamisation techniques (Augat and von Rüden, 2018). Compression plates achieve absolute stability (Gautier et al., 1992), and locking plates are exploited in varied configurations to facilitate relative stability between fracture fragments (Kandemir, 2018). The quality of reduction, implant design and material, length and position of plate, screw type and configuration affect the mechanical strength of plating construct, and consequently the rate of healing. Decades of research reveal that overly rigid fixation supresses callus formation and biological bone healing, leading to delayed union, non-union, osteolysis and fixation failure (Hak et al., 2010). However, allowing micromotion at fracture site, known as dynamisation, stimulates callus formation, resulting in faster and stronger healing (Goodship and Kenwright, 1985). Thus the design of bone plates requires fixation yet also the capacity for micromotion. Recent developments in bone plate design have aimed to achieve these opposing yet simultaneous requirements (Henschel et al., 2017), albeit through generic design.

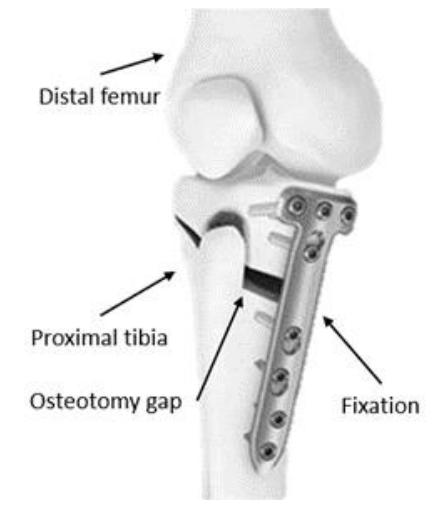

Figure 1: High tibial osteotomy and fixation (Reproduced with permissions from DePuy Synthes Trauma) [From TomoFix Medial High Tibial Plate (MHT) technique guide]

HTO is a widely recognised treatment for patients who have unicompartmental arthritis with malalignment of the mechanical axis (Röderer et al., 2014). The clinical aim of the surgery (Figure 1), is to create an osteotomy gap which corrects the mechanical abnormality of disproportionate loading of the tibiofemoral compartment by redistributing weight-bearing loads to relieve pain and optimise the joint movement. In a retrospective study, Röderer et al. (2014), found incomplete osteotomy healing and cortical deficiency in patients treated with HTO, attributed to the lack of interfragmentary motion (micromotion) adjacent to the plate resulting from high stiffness of locking plates. Therefore there are two challenges in the design of fixation devices for HTO. Firstly the fixation requires stability yet micromotion, which inherently impacts the type of healing. Secondly, that high stiffness of fixation also inhibits healing. Overcoming these challenges for HTO has a follow on impact in the design for fixation devices for all fractures. 
Recent advances in manufacturing and the paradigm shift towards digital frameworks, vastly increase the design space for medical devices. An example of this would be the widely acknowledged increase in topology freedom, afforded by Additive Manufacturing (AM) platforms. Nevertheless, the freedom in topology offered by AM, is constrained by the psychological inertia of the design engineer to Design for Manufacture in a subtractive manner (Thomas-Seale et al., 2018). Whilst AM provides an opportunity to increase the specificity of the design of implants to the patient physiology or pathology, in the literature this is predominately limited to patient specific geometry for example in cranial and maxillofacial implants (Tack et al., 2016). Burton et al. (2019), broached the challenge of replicating physiological mechanical properties through lattice design. To date, this is the only example of exploiting the creative design potential of AM, to increase the specificity of implants beyond geometry.

The purpose of this study, is to overcome the challenge of psychological inertia which limits Design for Manufacture of fixation devices, through the inventive principles and design tools of the Theory of Inventive Problem Solving (TRIZ) (Gadd et al., 2011). The aim is to evaluate whether the use of inventive design principles can increase the patient specificity of fixation for HTO, shall be met through the following objectives. As per the Double Diamond design framework, (Design Council, 2018), the problem shall be expanded through a Functional Analysis of current techniques and a spatiotemporal decomposition of a problem through the 9-Boxes tool. From these analyses the Ideal Outcomes shall be identified. The Inventive Principles shall be used to create concepts which satisfy the Ideal Outcomes. Finally the concepts will be evaluated against the Ideal Outcomes using the Analytic Hierarchy Process (AHP) (Saaty, 1980), to ascertain whether the TRIZ Inventive Principles have generated novel and feasible solutions to the expanded problem scope.

\section{METHOD}

Functional Analysis was applied to expand on the system interactions between a compression plate and the bone. The TRIZ functional analysis (Gadd et al., 2011) develops this traditional design tool, to consider the types of interaction between system components. The Functional Analysis (Figure 2) was created using MindManager 2018 (Mindjet, San Francisco, USA). The action, in which one component causes change to another component, can be defined as useful, insufficient or harmful, distinguished by arrow colour and style. The outcomes of this tool show how the harmful effects (high stability and high stiffness), are intrinsically linked to the useful outcomes.

To expand the perspective on when the harms occur and when the useful functions are required, The "Thinking in Time and Scale" 9-Boxes tool was applied (Figure 3). This tool facilitates a spatiotemporal decomposition of a problem; allowing the context, solution or system to be broken down across time (past, present and future) and scale (sub-system, system and super-system) (Gadd et al., 2011). This tool can be tailored to requirements of the system. In this instance 4 time points were used. The type of fracture healing, changes immediately after fracture through to 6 weeks and is influenced by fixation stability. Beyond 6 weeks, the bone remodelling phase is influenced by fixation stiffness. The main outcome of this tool is how the ideal requirements of the fixation device change with time.

Prior to the conceptual design phase the ideal solution must be identified. The Ideal Outcome (Gadd et al., 2011) allow the design to be evaluated against the ideal requirements of the fixation device. This tool was informed by the outcomes of the Functional Analysis and 9-Boxes analyses. Notably the ability to control the stiffness, to avoid stress shielding, and the micromotion, to tailor the implant to optimum healing. In addition, the Ideal Outcome considers DfAM in terms of materials, manufacturability, postprocessing and inspection. The ideal requirements of the fixation devices are presented in column 1 of Figure 4. Stiffness of the fixation is required at the point and time of fracture, however in the remodelling phase ( $>6$ weeks) this can cause stress shielding through the surrounding bone. Stability is required at the point and time of fracture, however in the ossification phase ( $<6$ weeks) less stability is required to stimulate secondary healing.

To develop the concept designs the TRIZ Inventive Principles described by Gadd et al. (2011) to solve physical contradictions were applied. Physical contradictions refer to the existing need of opposite features/solutions in the same system. The physical contradictions identified in this study are stability and stiffness. To solve these physical contradictions, the Inventive Principles were utilised in term of separating in space, time and condition (Gadd et al., 2011). These are outlined in Table 1. Decomposing the problem in time was applied to stability, decomposing in space and condition was applied to 
stiffness, and finally to generate a concept design to change both the stability and stiffness, the design was separated in time, space and condition. The concept designs were generated subject to the following constraints: materials were limited to titanium and polylactic acid (PLA), both of which are biocompatible and may be additively manufactured. The topology of the design principles are visually represented in Table 2; generated using SolidWorks 2016 (Dassault Systèmes, Vélizy-Villacoublay, France) and Netfabb 2018 (Autodesk, California, United States).

Finally, the concept designs were evaluated using the AHP (Figure 4), a tool based on a set of pairwise comparisons that depend on the designers perception to evaluate and prioritise options in a multi-criteria decision making process ( $\mathrm{Mu}$ and Making, 2015). The decision making process is hierarchically decomposed, level 1 (goal) evaluation of the design principles, level 2 (criteria), the Ideal Outcomes and level 3 (alternatives) the concept design solutions. Equal importance was given to the Ideal Outcomes of tailored rigidity and stiffness due to their impact on the process of healing. At first the Ideal Outcomes were weighted, and then for a fixed Ideal Outcome, a score was assigned based on the design concept's ability to satisfy that Ideal Outcome. Saaty's pairwise comparison scale (Saaty, 1980) was used as benchmark to evaluate the concept design principles against the Ideal Outcomes. The weighted scores were then multiplied by an arbitrary value of 100 for ease of interpretation. Finally, the global score for each concept design was determined by summing up all weighted scores specific to each design and thus final ranking. Any bias in the decision making process was minimised by checking for the consistency of the evaluations using the consistency ratio recommended by Thomas Saaty.

\section{RESULTS}

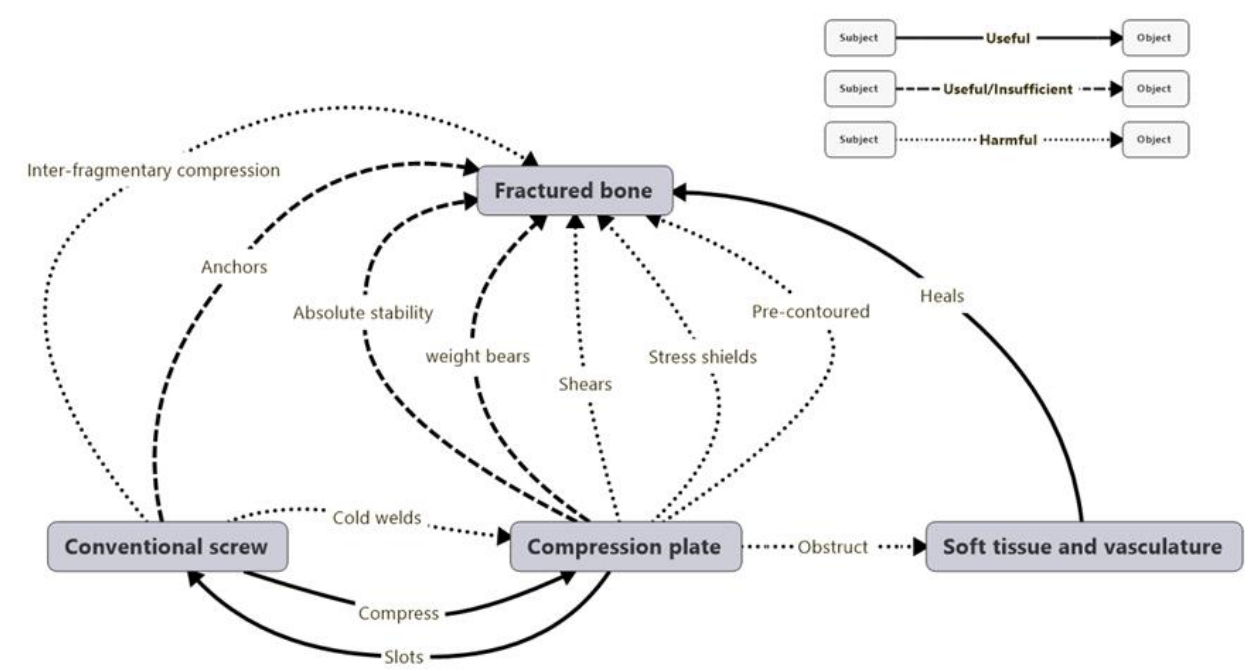

Figure 2: Functional analysis of conventional compression plate fracture fixation induces primary healing

A Functional Analysis of conventional fracture fixation using a compression plate is shown in Figure 2. A compression plate is one of the two fixation methods used for bone fracture, the other is the locking plate. Whilst this fixation method induces primary healing, it also create a series of harmful side effects including vasculature obstruction, cold welds and stress shielding. Most pertinently, the compression plate induces absolute stability, which induces healing but in an insufficient manner.

The 9-Boxes tool, shown in Figure 3 expands these observation to give further information about when and where the harms and healing occur. Figure 3 (1) maps the context of the problem (fracture and the two current clinical solutions, locking plates and compression plates), (2) captures the needs of the system (requirements of a fixation) and (3) identifies the relationship between the fixation stability and stiffness and the type of healing. The outcomes of this analysis which inform both the Ideal Outcomes and the Physical Contradiction toolset is the change in the requirements of fixation between the point of trauma and pre and post first 6 weeks of healing. Whilst the fracture needs to be immobilised absolutely immediately after the trauma, as the healing period begins the type of fixation impacts on the type of healing. The ideal type of fixation will change from absolute to relative stability inducing the more efficient type of secondary healing stimulating both intramembranous and 
endochondral ossification. Similarly, at the point of fracture the fixation device needs to be stiff, to immobilise the wound, but beyond 6 weeks, if the stiffness of the fixation is higher than the surrounding bone, the device will cause stress shielding leading to loss of bone density. Thus the Ideal Outcomes, listed in Figure 4, include the design capacity to achieve localised mechanical properties (spatially varying stiffness) and design capacity to achieve time-varying micromotion (temporally varying rigidity). Additional Ideal Outcomes are listed under Design and Manufacture and Function. The Design and Manufacture parameters are common in the assessment of DfAM of any biomedical implant. The function and biological requirements are more unique to this clinical problem, and were extracted from the Functional Analysis and 9-boxes.

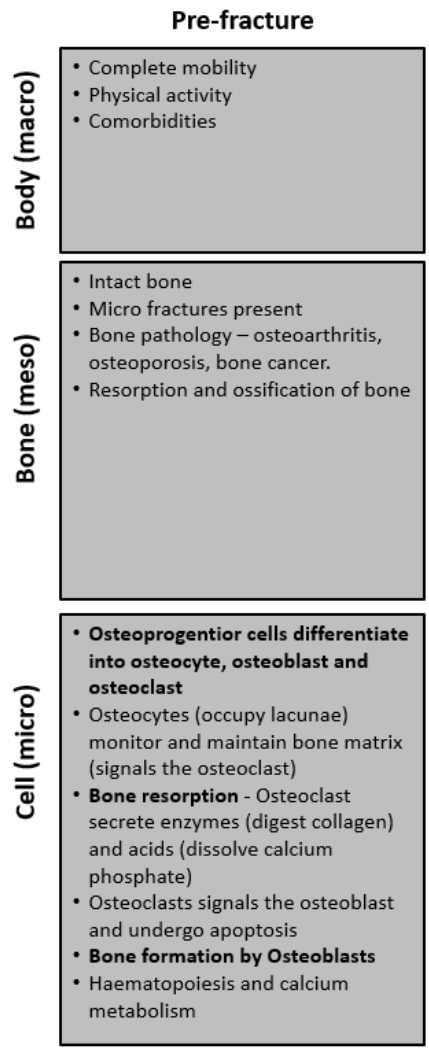

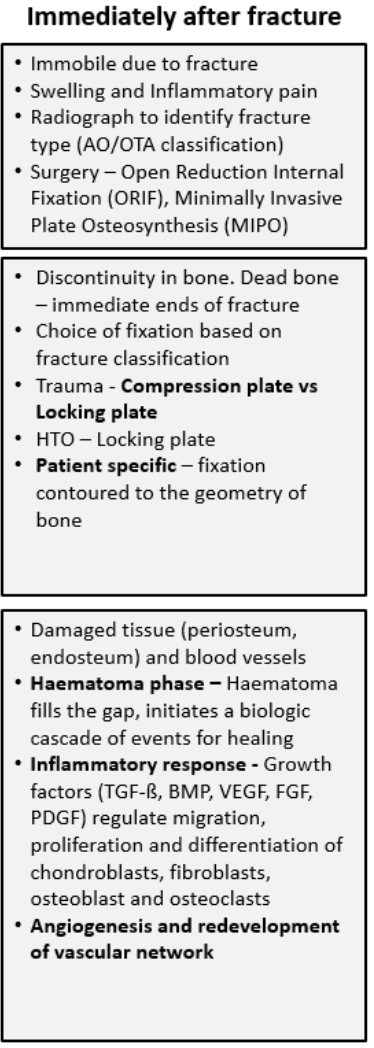

6 weeks >

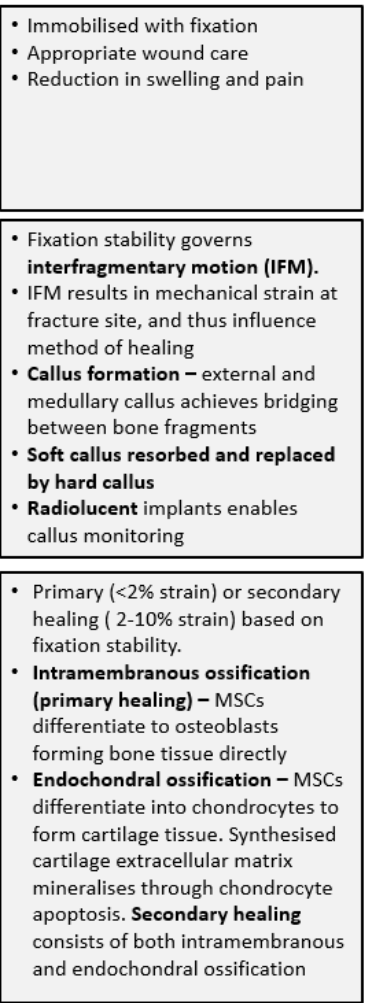

Figure 3: Time and scale analysis of fracture healing

Table 1: TRIZ inventive principles used for solving physical contradiction

\begin{tabular}{|l|c|r|}
\hline Separate in Time & Separate in Space & Separate on Condition \\
\hline Segmentation & Segmentation & Porous material \\
Nested doll & Nested doll & Parameter change \\
Dynamics & Extraction & \\
& Local quality & \\
& Composite materials & \\
& Asymmetry & \\
\hline
\end{tabular}

The Ideal Outcomes also pose physical contradictions. The ideal requirement of an HTO fixation would be stiff construct with absolute stability to stabilise the fracture, which over time changes to be less stiff with relative stability to induce faster healing and avoid stress shielding. These opposite requirements were solved by separating the solutions in time, space and condition to have both opposite solutions in the same system (Gadd et al. (2011)). The Inventive Principles used to generate each concepts designs are outlined in Table 1. The conceptual designs for the macro structure or meso design of the fixation device are shown in Table 2, with respect to the Inventive Principles that were used to generate them. There are 3 themes, around which 6 concepts were developed. The Dynamisation theme refers to the ability to control interfragmentary micromotion. Stiffness Modulation, refers to the ability to tailor the spatial stiffness of the implant. It is hypothesized that an 
optimum fixation solution would be designed with controllable stability and stiffness over time. Dynamisation Modulation, is the temporal modulation of a dynamisation mechanism.

Table 2: Concept and design principles

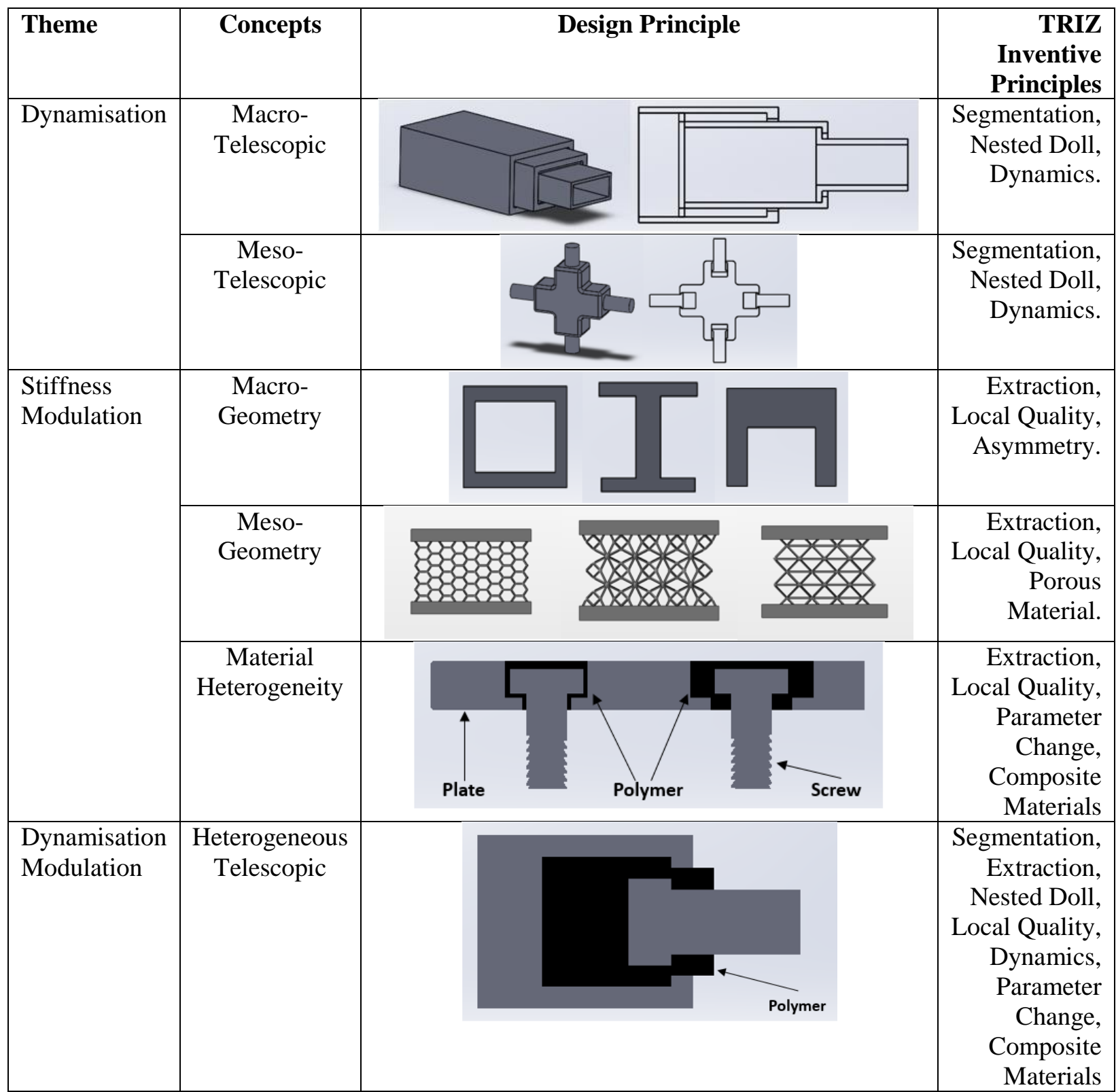

Under the theme of Dynamisation, there are two solutions; a telescopic approach at the macro and meso scale. Macro is the same scale as the bone and fixation device and meso is in the scale of material in millimetres. These telescopic approaches generate dynamisation through the Inventive Principles of Nested Doll, Segmentation and Dynamics. The TRIZ Nested Doll principle, places an object inside another object (Gadd et al., 2011), for example the principle that governs a telescope or umbrella. Segmentation and Dynamics are respectively defined as making an object sectional and changing the performance of a part at each stage of operation (Gadd et al., 2011). Under the stiffness modulation theme there are 3 conceptual design: macro, meso and a Material Heterogeneity design. Design for stiffness modulation relative to the Meso-Geometry of the material, incorporates lattices envisaged from the Inventive Principles of Material Extraction (extracting only the required property of an object), local Quality (non-uniform structure) and Porous Materials (to make an object porous) (Gadd et al., 2011). Alternatively the Macro- Geometry design for stiffness modulation incorporates the Inventive Principles of Extraction and Local Quality, and in addition Symmetry (removing the symmetric nature of an object) (Gadd et al., 2011). Finally, stiffness modulation can be achieved through Material Heterogeneity of bone plate design incorporating multiple materials, for example the 
incorporate of PLA into a titanium implant. This concept generated was from the Inventive Principle of Extraction, Local Quality, Parameters Change (changing a parameter such as state) and Composite Materials (change from uniform to composite materials) (Gadd et al., 2011). The Dynamisation Modulation theme has one concept design, the Heterogeneous Telescopic design, which was generated through a combination of the Inventive Principles utilised in the Stiffness Modulation and Dynamisation theme, specifically those used to generate the two telescopic and Material Heterogeneity design.

\begin{tabular}{|c|c|c|c|c|c|c|c|c|c|c|c|c|c|c|}
\hline \multirow{3}{*}{ Ideal outcomes } & \multirow{3}{*}{ 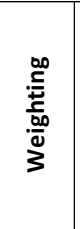 } & \multirow{3}{*}{ 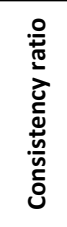 } & \multicolumn{4}{|c|}{ Dynamisation } & \multicolumn{6}{|c|}{ Stiffness Modulation } & \multirow{2}{*}{\multicolumn{2}{|c|}{\begin{tabular}{|c|}
$\begin{array}{c}\text { Dynamisation } \\
\text { Modulation }\end{array}$ \\
$\begin{array}{c}\text { Heterogeneous } \\
\text { Telescopic }\end{array}$ \\
\end{tabular}}} \\
\hline & & & \multicolumn{2}{|c|}{$\begin{array}{l}\text { Macro- } \\
\text { Telescopic }\end{array}$} & \multicolumn{2}{|c|}{$\begin{array}{l}\text { Meso- } \\
\text { Telescopic }\end{array}$} & \multicolumn{2}{|c|}{$\begin{array}{l}\text { Macro- } \\
\text { Geometry }\end{array}$} & \multicolumn{2}{|c|}{$\begin{array}{l}\text { Meso- } \\
\text { Geometry }\end{array}$} & \multicolumn{2}{|c|}{$\begin{array}{c}\text { Material } \\
\text { Heterogeneity }\end{array}$} & & \\
\hline & & & Score & $\begin{array}{l}\text { Weighted } \\
\text { Score }\end{array}$ & Score & \begin{tabular}{c|} 
Weighted \\
score
\end{tabular} & Score & $\begin{array}{l}\text { Weighted } \\
\text { score }\end{array}$ & Score & $\begin{array}{c}\text { Weighted } \\
\text { score }\end{array}$ & Score & $\begin{array}{c}\text { Weighted } \\
\text { score }\end{array}$ & Score & $\begin{array}{l}\text { Weighted } \\
\text { score }\end{array}$ \\
\hline \multicolumn{15}{|l|}{$\begin{array}{l}\text { Design and Manufacture } \\
\text { Requirements }\end{array}$} \\
\hline Design Complexity & 0.205 & 0.08 & 0.073 & 1.5 & 0.051 & 1.1 & 0.457 & 9.3 & 0.194 & 4.0 & 0.194 & 4.0 & 0.030 & 0.6 \\
\hline $\begin{array}{l}\text { Cost of (proposed) } \\
\text { Materials }\end{array}$ & 0.046 & 0.00 & 0.214 & 1.0 & 0.214 & 1.0 & 0.214 & 1.0 & 0.214 & 1.0 & 0.071 & 0.3 & 0.071 & 0.3 \\
\hline Manufacturability & 0.341 & 0.08 & 0.064 & 2.2 & 0.043 & 1.5 & 0.409 & 13.9 & 0.207 & 7.1 & 0.246 & 8.4 & 0.031 & 1.1 \\
\hline Ease of Assembly & 0.057 & 0.03 & 0.053 & 0.3 & 0.053 & 0.3 & 0.376 & 2.2 & 0.376 & 2.2 & 0.115 & 0.7 & 0.027 & 0.2 \\
\hline Ease of Post-processing & 0.113 & 0.02 & 0.044 & 0.5 & 0.044 & 0.5 & 0.552 & 6.2 & 0.075 & 0.9 & 0.208 & 2.4 & 0.077 & 0.9 \\
\hline Ease of Validation & 0.125 & 0.05 & 0.060 & 0.7 & 0.060 & 0.7 & 0.554 & 6.9 & 0.091 & 1.1 & 0.205 & 2.6 & 0.031 & 0.4 \\
\hline Ease of Inspection & 0.113 & 0.07 & 0.082 & 0.9 & 0.046 & 0.5 & 0.535 & 6.0 & 0.075 & 0.8 & 0.230 & 2.6 & 0.032 & 0.4 \\
\hline Sum & 1.0 & & & 7.1 & & 5.6 & & 45.6 & & 17.0 & & 20.9 & & 3.8 \\
\hline \multicolumn{15}{|l|}{$\begin{array}{l}\text { Functional and Biological } \\
\text { Requirements }\end{array}$} \\
\hline $\begin{array}{l}\text { Wear between Interfacing } \\
\text { Surface }\end{array}$ & 0.120 & 0.07 & 0.035 & 0.4 & 0.033 & 0.4 & 0.383 & 4.6 & 0.359 & 4.3 & 0.136 & 1.6 & 0.053 & 0.6 \\
\hline $\begin{array}{l}\text { Design Capacity to Achieve } \\
\text { Local Mechanical Properties }\end{array}$ & 0.266 & 0.08 & 0.029 & 0.8 & 0.034 & 0.9 & 0.220 & 5.9 & 0.427 & 11.3 & 0.209 & 5.6 & 0.081 & 2.2 \\
\hline $\begin{array}{l}\text { Design Capacity to Achieve } \\
\text { Time-Varying Micromotion }\end{array}$ & 0.336 & 0.01 & 0.186 & 6.3 & 0.212 & 7.1 & 0.025 & 0.8 & 0.042 & 1.4 & 0.123 & 4.1 & 0.411 & 13.8 \\
\hline $\begin{array}{l}\text { Geometric Patient- } \\
\text { specificity }\end{array}$ & 0.120 & 0.03 & 0.033 & 0.4 & 0.045 & 0.5 & 0.301 & 3.6 & 0.301 & 3.6 & 0.290 & 3.5 & 0.031 & 0.4 \\
\hline Ease of Implant Removal & 0.120 & 0.04 & 0.035 & 0.4 & 0.047 & 0.6 & 0.354 & 4.3 & 0.354 & 4.3 & 0.178 & 2.1 & 0.032 & 0.4 \\
\hline $\begin{array}{l}\text { Radiolucent (able to } \\
\text { monitor callus formation) }\end{array}$ & 0.038 & 0.01 & 0.059 & 0.2 & 0.059 & 0.2 & 0.418 & 1.6 & 0.053 & 0.2 & 0.360 & 1.4 & 0.051 & 0.2 \\
\hline Sum & 1.0 & & & 8.5 & & 9.8 & & 20.7 & & 25.1 & & 18.3 & & 17.6 \\
\hline Global score & & & & 15.6 & & 15.3 & & 66.3 & & 42.2 & & 39.2 & & 21.4 \\
\hline Rank & & & & 5 & & 6 & & 1 & & 2 & & 3 & & 4 \\
\hline
\end{tabular}

Figure 4: Evaluation of design principles

The evaluation matrix illustrates a concept design's ability to fulfil the Ideal Outcomes extracted through the problem mapping. Design complexity, manufacturability, design capacity to achieve local mechanical properties and design capacity to achieve micromotion were prioritised as result of using the AHP methodology. Comparatively the cost of materials, ease of assembly and radiolucency are weighted less heavily. Nonetheless, all Ideal Outcomes carried weight in the ranking of the design solutions. The Stiffness Modulation Macro-Geometry, Meso-Geometry and Material Heterogeneity designs were ranked the highest. Stiffness Modulated Macro-Geometry outscored all other concepts against the Ideal Outcomes grouped under Design and Manufacture. Meso-Geometry was judged to be the most capable to achieve localised mechanical properties. In particular, the Meso-Geometry was 
preferred over the Macro-Geometry when considering the functional and biological requirements. The Heterogeneous Telescopic design ranked the highest for the design capacity for time-varying micromotion. Under the Dynamisation theme, the Macro-Telescopic and Meso-Telescopic design concepts were shown as weak solutions for achieving time varying micromotion. The consistency ratios assessed in scoring of the design (Figure 4) and weighting of the Ideal Outcomes adhere to the recommended value of $<0.1$ using the AHP method, emphasising minimal inconsistency in the pairwise decision making process (Mu and Making, 2015).

\section{DIsCUSSION}

Fracture healing, is a physiologically complex process that involves both biological and mechanical aspects. The surgeon determines the choice of fixation based on fracture classification, accounting for fracture pattern, location, bone quality, and location of plate placement dictated by the anatomy (DeCamp et al., 2016). At present, two distinct plating techniques are used to bridge trauma factures, the compression plate and locking plate. The Functional Analysis tool (Figure 2) demonstrates that whilst the compression plate induces stress shielding and the conventional screw induces insufficient inter-fragmentary motion, that the design itself also anchor the fracture, bears the weight of the discontinued bone and heals the fracture albeit not in the most efficiently manner.

The 9-Boxes tool (Figure 3) was used to expand the interactions between healing and the fixation device. This tool highlights the biological reasons behind the time and scale dependency of stability and stiffness, and pinpoints the exact time specification of these physically contradicting requirements. The 'pre-fracture' column elucidates the mechano-biology of remodelling, where resorption and ossification of bone occurs in response to mechanical loading (Ghiasi et al., 2017). The second column through to the fourth, illustrate the biological cascade of events which activate the healing process, commencing with haematoma, followed by an inflammatory response, instigating the formation of external and medullary callus, ends with the indefinite remodelling phase (Marsell and Einhorn, 2011). Mechanical stability provided by fixation plates govern the method of healing. Depending on their innate design, absolute or relative stability is attained and the healing process is primary or secondary respectively. Primary healing (intramembranous ossification) is induced by absolute stability, and the more efficient secondary healing, characterised by callus formation, occurs by means of relative stability comprising both intramembranous and endochondral ossification (Jagodzinski and Krettek, 2007). Even though HTO demands an intricate surgical procedure compared to trauma fractures, it favours the locking plate over the compression plate as fixation which allows inter-fragmentary motion, thus more efficient secondary healing via both healing methods (Röderer et al., 2014).

To dynamise bone plates and facilitate the micromotion required to stimulate option healing, current solutions incorporate various mechanics that revolve around increasing the motion around the fixation of the screw to the bone (Bottlang et al., 2009, 2017; Döbele et al., 2010). The stiffness modulation of orthopaedic implants and has been broached only once, by varying the lattice design of a hip implant (Burton et al., 2019). The design of biomedical implants for time-varying biological requirements, is something unique to this study, as yet unbroached by DfAM literature. As such, the design capacity to achieve time-varying stability and spatially varying stiffness are prioritised in the Ideal Outcomes, along with the design complexity and manufacturability, which are key to assessing the potential success of the design via additive manufacture.

However, the Ideal Outcomes of micromotion and localised mechanical properties are inherently physical contradictions. Thus the Inventive Principles in Table 1, which are evaluated below, were employed to generate three design themes. Dynamisation concepts, offer flexible fixation, Stiffness Modulation offers localised spatial design and Dynamisation Modulation yields time-controlled change in fixation. Each concept design, Table 2, shall be discussed in line with its evaluation in Figure 4.

The three Stiffness Modulation designs were ranked the highest, followed by Dynamisation Modulation and finally novel Dynamisation techniques. This primarily comes down to the complexity of the design versus the number of benefits that it yields. The Dynamisation approach, both macro and meso, employed the telescopic approach which has fundamental design challenges in controlling the load bearing capacity, the wear between the components and the post-processing of such a design. The Stiffness Modulated design, both macro and meso, offered localisation of the mechanical properties of the bone plate, relative to the physiological loading environment, via lattices or the macro design 
respectively. Whilst the Meso-Geometry design raises issues with post-processing and inspection, the Macro-Geometry design presents a simple yet elegant solution. This design is inherently manufactureable and ranks highly on almost all the functional and biological requirements. The key draw-back of this design is the lack of design capacity to achieve micromotion. However, it should be noted, that any of these three stiffness modulated designs in Figure 4, could also incorporate dynamisation through micromotion between the screw and plate, as incorporated in the locking plate (Henschel et al., 2017). Finally the Material Heterogeneity design, generated issues similar to the telescopic and lattice structures in terms of post-processing. The Material Heterogeneity concept further increased the complexity of the design by requiring multiple biocompatible and manufacturing compatible materials. Finally the Dynamisation Modulation approach utilised aspects of the telescopic and Material Heterogeneity designs. The benefit of this approach was that some of the limitations of the original telescopic approaches, were overcome by the integration of multiple materials. Multimaterial design offers the capacity to change the components of the plate, through integration of biodegradable materials, i.e. materials which degrade over time (for example PLA), thus controlled reduction in load bearing capacity. However, ultimately this design still suffers from shortcomings in very complex design and manufacturability.

The TRIZ Inventive Principles have inspired six design solutions by addressing the existing physical contradictions in the system. In this context, Asymmetry, Extraction and Local Quality, and decomposing the problem spatially can be considered robust Inventive Principles because they led to highly ranked macro and meso stiffness modulated design. Similarly, Porous Material and Parameter Change were successful when stiffness modulation was addressed through condition separation i.e. Material Heterogeneity. Nested Doll, Segmentation and Dynamics have generated design solutions to achieve micromotion but they led to the solutions that were evaluated as weakest.

The evaluation process using the AHP captures both qualitative and quantitative aspects of a decision making process. The assignment of preference in the pairwise comparisons was also checked. However limitations were introduced to the research due to the subjective nature of conducting and interpreting the TRIZ problem mapping tools, Inventive Principles and the ranking of the Ideal Outcomes. Further research is required to develop and technically evaluate these concept designs.

\section{CONCLUSION}

This study presents an application of TRIZ design principles and an evaluation of Inventive Principles to generate concept design for dynamised and stiffness modulated fixation for HTO. The Ideal Outcomes of the design were extracted from problem mapping of fracture pathology and current solutions for fixation. Ideally the fixation needs to be tailored specifically for the healing mechanisms of fracture. However this requirement also poses physical contradictions; the fixation needs to be able to change its stability and stiffness. These physical contradictions were solved using the TRIZ Inventive Principles, which inspired the development of design principles satisfying the varying requirements of stability and stiffness. The concept designs were then evaluated against the Ideal Outcomes using the AHP. The evaluation of the designs, against the requirements of design, manufacture, functional and biological factors, ranked Stiffness Modulation through Macro-Geometry of the fixation shape the highest. From the outcomes of the evaluation of each concept the Inventive

Principles of Asymmetry, Extraction and Local Quality were determined as the most robust in this context.

\section{REFERENCES}

Augat, P. and von Rüden, C. (2018), "Evolution of fracture treatment with bone plates”, Injury. Elsevier Ltd. All rights reserved., Vol. 49 No. June, pp. S2-S7. https://doi.org/10.1016/S0020-1383(18)30294-8.

Bottlang, M. et al. (2009), "Far cortical locking can reduce stiffness of locked plating constructs while retaining construct strength”, Journal of Bone and Joint Surgery - Series A, Vol. 91 No. 8, pp. 1985-1994. https://doi.org/10.2106/JBJS.H.01038.

Bottlang, M. et al. (2017), "Dynamic stabilization of simple fractures with active plates delivers stronger healing than conventional compression plating”, Journal of Orthopaedic Trauma, Vol. 31 No. 2, pp. 71-77. https://doi.org/10.1097/BOT.0000000000000732.

Burton, H.E. et al. (2019), "The design of additively manufactured lattices to increase the functionality of medical implants”, Materials Science and Engineering: C. Elsevier, Vol. 94 No. March 2018, pp. 901908. https://doi.org/10.1016/j.msec.2018.10.052. 
Court-Brown, C.M. and Caesar, B. (2006), "Epidemiology of adult fractures: A review”, Injury, Vol. 37 No. 8 , pp. 691-697. https://doi.org/10.1016/j.injury.2006.04.130.

DeCamp, C.E. et al. (2016), "2 - Fractures: Classification, diagnosis, and treatment”, Brinker, Piermattei and Flo's Handbook of Small Animal Orthopedics and Fracture Repair, pp. 24-152. https://doi.org/10.1016/B978-1-4377-2364-9.00011-2.

Döbele, S. et al. (2010), "The dynamic locking screw (DLS) can increase interfragmentary motion on the near cortex of locked plating constructs by reducing the axial stiffness", Langenbeck's Archives of Surgery, Vol. 395 No. 4, pp. 421-428. https://doi.org/10.1007/s00423-010-0636-z.

Ensrud, K.E. (2013), "Epidemiology of fracture risk with advancing age”, Journals of Gerontology - Series A Biological Sciences and Medical Sciences, Vol. 68 No. 10, pp. 1236-1242. https://doi.org/10.1093/gerona/glt092.

Gadd, K. et al. (2011), "Triz for engineers: Enabling inventive problem solving”, TRIZ for Engineers: Enabling Inventive Problem Solving. Wiley, p. 504. https://doi.org/10.1002/9780470684320.

Gautier, E. et al. (1992), “(iii) Principles of internal fixation”, Current Orthopaedics, Vol. 6 No. 4, pp. $220-232$. https://doi.org/10.1016/0268-0890(92)90019-A.

Ghiasi, M.S. et al. (2017), "Bone fracture healing in mechanobiological modeling: A review of principles and methods", Bone Reports. Elsevier Inc., Vol. 6, pp. 87-100. https://doi.org/10.1016/j.bonr.2017.03.002.

Goodship, A.E. and Kenwright, J. (1985), "The influence of induced micromovement upon the healing of experimental tibial fractures", The Journal of bone and joint surgery. British volume, Vol. 67 No. 4, pp. 650-655. https://doi.org/10.1007/978-1-4471-5451-8_131.

Hak, D.J. et al. (2010), "The influence of fracture fixation biomechanics on fracture healing", Orthopedics, Vol. 33 No. 10, pp. 752-755. https://doi.org/10.3928/01477447-20100826-20.

Henschel, J. et al. (2017), "Comparison of 4 methods for dynamization of locking plates: Differences in the amount and type of fracture motion”, Journal of Orthopaedic Trauma, Vol. 31 No. 10, pp. 531-537. https://doi.org/10.1097/BOT.0000000000000879.

Hernlund, E. et al. (2013), "Osteoporosis in the European Union: Medical management, epidemiology and economic burden: A report prepared in collaboration with the International Osteoporosis Foundation (IOF) and the European Federation of Pharmaceutical Industry Associations (EFPIA)", Archives of Osteoporosis, Vol. 8 No. 1-2. https://doi.org/10.1007/s11657-013-0136-1.

Jagodzinski, M. and Krettek, C. (2007), "Effect of mechanical stability on fracture healing-an update", Injury, Vol. 38 Suppl 1(1), pp. S3-10. https://doi.org/10.1016/j.injury.2007.02.005.

Johnell, O. and Kanis, J.A. (2004), “An estimate of the worldwide prevalence, mortality and disability associated with hip fracture”, Osteoporosis International, Vol. 15 No. 11, pp. 897-902. https://doi.org/10.1007/s00198-004-1627-0.

Kandemir, U. (2018), "Distal femur: dynamization of plating”, Injury. Elsevier Ltd. All Rights Reserved., Vol. 49 No. June, pp. S44-S48. https://doi.org/10.1016/S0020-1383(18)30302-4.

Marsell, R. and Einhorn, T.A. (2011), “The biology of fracture healing”, Injury. Elsevier Ltd, Vol. 42 No. 6, pp. 551-555. https://doi.org/10.1016/j.injury.2011.03.031.

Mu, E. and Making, P.D. (2015), Understanding the Analytic Hierarchy Process, No. 2012. https://doi.org/10.1007/978-3-319-33861-3.

Röderer, G. et al. (2014), "Delayed bone healing following high tibial osteotomy related to increased implant stiffness in locked plating”, Injury, Vol. 45 No. 10, pp. 1648-1652. https://doi.org/10.1016/j.injury.2014.04.018.

Saaty, T.L. (1980), The Analytic Hierarchy Process. McGraw-Hill, New York.

Tack, P. et al. (2016), "3D-printing techniques in a medical setting: A systematic literature review", BioMedical Engineering Online. BioMed Central, Vol. 15 No. 1, pp. 1-21. https://doi.org/10.1186/s12938-016-0236-4.

The Design Process: What is the Double Diamond?|Design Council (no date). Available at: https://www.designcouncil.org.uk/news-opinion/design-process-what-double-diamond (Accessed: 30 November 2018).

Thomas-Seale, L.E.J. et al. (2018), "The barriers to the progression of additive manufacturing: an industrial review", Unpublished. Elsevier Ltd, Vol. 198 No. January, pp. 104-118. https://doi.org/10.1016/j.ijpe.2018.02.003.

\section{ACKNOWLEDGEMENTS}

The authors would like to acknowledge the UK Engineering and Physical Research Sciences National Productivity Investment Fund. 